\title{
Pelvis ve asetabulum kırıklarında kaynamama
}

\author{
Pelvic and acetabular non-unions
}

\author{
Özgür Şahin, Kadir Bahadır Alemdaroğlu
}

SBÜ Ankara SAUM, Ankara

\begin{abstract}
Pelvik ve asetabular kaynamamalar nadir ancak oldukça zorlu komplikasyonlardır. Pelvik kaynamamalar sıklıkla yanlış kaynamalar ile beraberdir. Bu komplikasyonların geliştikten sonra tedavisi oldukça zorlu olacağından, gerçekleşmeden önce önlenmesi için, özellikle pelvik kırıkların eşlik ettiği politravmalı hastalarda tedbir alınmalı; etkin cerrahi tedavi şansı olan ilk üç hafta periyodu kaçırılmamalıdır. Semptomatik pelvik kırık kaynamama olgularında cerrahi korreksiyon tercih edilmelidir. Cerrahi tedavi, kaynamama bölgesinin debridmanı, kırık uçlarının yaklaştırılması, aradaki boşluğun kemik grefti ile doldurulması ve dengeli içeriden tespittir. Kompleks vertikal instabil pelvik kaynamama ve yanlış kaynamalarda aşamalı bir prosedür izlenir. Illk aşamada prone pozisyonda geniş bir posterior gevşetme uygulanır; daha sonra supin pozisyonda hem ön hem arka deformite ve kaynamama bölgeleri açılır, gevşetilir, düzeltilir, redükte ve tespit edilir; en son olarak da hasta tekrar prone pozisyona getirilip posterior pelvik halka redükte edilir ve posterior sta-bilizasyon ilave edilir.
\end{abstract}

Anahtar sözcülkler: pelvis kırı̆ı; asetabulum kırı̆ı; ihmal edilmiş; kaynamama; yanlış kaynama; cerrahi tedavi
Pelvic and acetabular non-unions are rare but considerably demanding complications. Pelvic non-unions are frequently combined with malunions. As the treatment will be extremely challenging after the occurrence of a pelvic non-union, all efforts should be given not to pass the first three weeks after the injury, which is the effective period of the surgical treatment. Symptomatic pelvic non-unions should be treated surgically. The surgical treatment comprise debridement, approximating the fracture ends, filling the gaps with bone grafts, and stable internal fixation. A staged procedure should be followed in complex vertical instable pelvic non-unions and malunions. In the first stage an extensile posterior released should be done in prone position; followed by the exposure, release, correction and reduction of both anterior and posterior structures in supine position. In the end, the patient is turned again to the prone position, allowing reduction of the posterior pelvic ring and then a posterior stabilization is added.

Key words: pelvis fracture; acetabular fracture; neglected; nonunion; malunion; surgical treatment
$\mathbf{P}$ elvis, ağırıklı olarak spongiyöz kemikten oluşur; bu yüzden, kanlanması vücuttaki birçok kemiğe göre çok daha zengindir. Bu nedenden dolayı, gerek pelviste gerekse asetabulumda kaynamama nadir komplikasyonlar arasındadır. Pelvik kaynamama ve yanlış kaynamalar, hem ortopedik cerrahlar hem de hastalar için oldukça zorlu problemlerdir. Bu iki komplikasyon genellikle bir arada gerçekleşir. ${ }^{[1]}$ İzole pelvik kaynamama oldukça nadir olduğundan, bu derlemede kısaca pelvik yanlış kaynamaya da değinilecektir. Yanlış kaynama, kaynamamadan daha sık görülürek deformite ve instabiliteye neden olur. Pennal ve Massiah ${ }^{[2]}$, pelvis kırıklarında kaynamamaya ilk dikkat çeken yazarlar olmuşlardır. Yaş ortalaması 35 olan 42 hastalarında bu komplikasyonu bildirmişler; daha çok genç hastaları etkileyen ve ciddi sekeller bırakan bir klinik durum olarak tanımlamışlardır.

\section{ETIYOLOJi}

Politravma, pelvis ve asetabulum kaynamama olgularının etiyolojisinde önemli yer tutar. Politravmalı hastaların yaklaşık \%20'sinde pelvik kırık mevcuttur. Politravmalı hastaların bakımı geliştikçe, bu yaralanmalardan sağ olarak kurtulan hastalarda pelvik kırık tespit insidansı artmaktadır. Aslında iyi bir erken tedavi bu komplikasyonlara karşı koruyucu olsa da, pelvik kaynamama ve yanlış kaynama günümüzde halen

- İletişim adresi: Kadir Bahadır Alemdaroğlu, SBÜ Ankara SAUM (Ankara Eğitim ve Araştırma Hastanesi), Ulucanlar Caddesi, Ulucanlar, Ankara, 06340 Tel: 0312 - 5953632 e-posta: balemdaroglu@gmail.com

- Geliș tarihi: 1 Kasım $2017 \quad$ Kabul tarihi: 1 Kasım 2017 
görülmektedir. ${ }^{[1]}$ Çoğu politravmalı hastada pelvik kırıklar ya gözden kaçmakta ya da diğer bölge travmalarının tedavisindeki bazı öncelikler bu kırıkların tedavisi için uygun zamanın kaçırılmasına neden olmaktadır. Bunun yanı sıra, bazı kliniklerde cerrahi deneyimin bu konuda yetersiz olması, deplase kırıklarda bile konservatif kalma kararına yol açmaktadır. Pelvis ve asetabulum kırıklarının ideal olarak ilk 10 gün en geç üç hafta içinde ameliyata alınması gerektiği konusunda fikir birliği vardır. ${ }^{[3]}$ Yaralanmadan sonraki 4-5 haftada tüm kırık hatları kallus ile hareket ettirilemez hale gelir. Ayrıca, pelvis ve asetabulum kırıklarının traksiyon veya eksternal tespit gibi yetersiz tedavi yöntemleri de kaynamamaya ve yanlış kaynamaya yol açabilmektedir. İhmal edilmiş bu tür pelvik kırık kaynamama ve yanlış kaynamaların tedavisi hem zorludur hem de birçok komplikasyonlara yol açabilir. Bu kaynamama ve yanlış kaynamaların tedavi sonuçları yüz güldürücü olmadığından, en iyi seçenek bu tür deformitelerin daha oluşmadan önlenmesidir.

Pelvik kırıklar sadece travma sonrası gelişmemektedir. Yaşlılarda, postmenopozal dönemde, radyoterapi sonrası ve steroid kullanımı takiben pelvik halkada patolojik ve yetmezlik kırıkları gelişebilmektedir. Bu kırıklarda kaynama birkaç aylık konservatif tedavi ile olmaktadır. Superior ve inferior pubik ramus orta kısım, en çok kırık gelişen ve kaynamama görülen bölgedir. Kaynamama olasılığı en yüksek pelvik kırıklar radyoterapi sonrası gelişenlerdir. ${ }^{[4]}$

\section{SINIFLANDIRMA}

Mears ve ark. ${ }^{[3]}$, pelvik kaynamama ve malalignment olgularını alttaki gibi sınıflamışlardır:

Tip 1: Deformasyon olmadan kaynamama

Tip 2: Stabil malalignment

Tip 3: İnstabil, kaynamamış malalignment

Tip 4: Kallus ve heterotopik kemik tarafından kısmi stabilizasyon sağlanan malalignment

\section{Tile Sınıflamasındaki Kırık Tiplerine Göre Pelvik Kaynamama}

Pelvik kaynamama olguları bölgesel olarak ön, arka ve lateral pelvis olarak ayrilabilir; genellikle arka pelvisin vertikal shear yaralanması sonucu görülür. ${ }^{[3,5,6]}$ Daha az sıklıkla, lateral kompresyon yaralanması arka pelviste kaynamamaya neden olabilir. Bu tür kaynamama olguları, Tile klasifikasyonuna göre Tip $B$ ve $C$ kırıkların yetersiz tedavisi neticesinde görülür. APC (anteroposterior kompresyon) tip yaralanma ön pelviste instabiliteye neden olabilirken, pubik kol ve iliak kanat kırıklarında kaynamama çok seyrektir.

\section{Letournel Sınıflamasındaki Asetabular Kırık Tipine Göre Kaynamama}

Asetabulum kırıklarında kaynamamanın en sık görüldüğü kırıklar izole transvers veya transvers + posterior duvar kırıklarıdır. ${ }^{[1]}$ Letourne[[7], asetabulum kırıklarında kaynamamayı dört ay geçmesine rağmen iyileşme olmaması olarak tanımlamıştır. Kaynamamanın, düz grafilerde kırık hattının net olarak, sklerotik kenarlar ve bazen hipertrofik irregüler kenarlar şeklinde görüldüğünü raporlamıştır. Literatürde, Mears 100 olguda bir kaynamama bildirmişken, Helfet ve Schmeling 127 cerrahi tedavi edilmiş kırıkta \%0 kaynamama bildirmiştir. ${ }^{[8,9]}$ Letournel, kendi serisinde cerrahi tedavi görmüş asetabulum kırıklarında kaynamama oranını $\% 0,7$ olarak bildirilmiştir. ${ }^{[7]}$

Mohanty, Taha ve Powell[10] kendi serilerinde, transvers ve posterior duvar tipindeki asetabulum kırıklarında her iki kolonun yetersiz tespitinin kaynamama gelişmesine yol açtığını ifade etmişlerdir. Bunun önüne geçmek için, her iki kolon için interfragmenter lag vidası tespiti ve tamamlayıcı olarak plak ve vida tespiti önermişlerdir.

\section{KLINIK SEMPTOMLAR}

\section{Ağrı}

Pelvik kırık kaynamama ve yanlış kaynama olgularında en sık rastlanılan semptomdur. ${ }^{[3,5,11]}$ Bunun nedeni; kırık redüksiyonunda yetersizlik ve sonuçta gelişen rezidüel deformitedir. Bu olgularda, ağrı yük verme ile artar, istirahat ile azalabilir. Hastalarda ağrının en sık köken aldığı bölge SI (sakroiliak) eklemdir. Hastaların çoğunda kaynamama veya yanlış kaynama pelvis arka kısmı ilgilendirdiğinden ve yük transferi de daha çok bu bölgeden iletildiğinden, ağrı bu bölgeden köken alır. Yine, sakrum kırıkları sıkıkla ihmal edildiğinden dolayı ağrı kaynağı olabilir. ${ }^{[12]}$

Anterior pelvik bölgede ihmal edilmiş kırıklarına bağI kaynamama daha az ağrıya neden olur. Bu nedenle tanı koymak daha zordur.

\section{Oturma ve Ayakta Durma Problemleri}

Hemipelvisin tek tarafinda deplasmana yol açan vertikal instabil kırıklar, pelvik oblisiteye, oturma imbalansına ve bacak uzunluk eşitsizliğine neden olabilir. ${ }^{[3]} \mathrm{SI}$ eklem veya yakınından kaynaklanan deformiteler daha çok rahatsızlığa yol açar. Oturma pozisyonunda ağrının bir nedeni de zeminle temas eden iskial çıkıntılar üzerinde eşitsiz yük dağılımıdır. Yine, hemipelvisin posteriora kayması, sakrumun veya posterior superior iliak spine aşırı çıkıntı yapması, oturma pozisyonunda ağrı ve rahatsızlığa yol açabilir. Bacak uzunluk eşitsizliği, 
vertikal shear kırıkların kaynamama veya yanlış kaynamasından sonra gelişebilir. Lateral kompresyon yaralanmaları bacakta internal rotasyona neden olabilir. Open book yaralanma bacakta eksternal rotasyon deformitesine sebebiyet verebilir. Yürüme güçlüğü en çok tip $C$ yaralanmalar sonucunda görülebilir.

\section{Cinsel ve Boşaltım Sistemi Disfonksiyonu}

Wright ve ark. ${ }^{[11]}$ pelvik kırıklı 298 hastada \%21 cinsel işlev, $\% 8$ boşaltım sistemi disfonksiyonu bulmuşlardır. Bu disfonksiyon, sakroiliak eklem yaralanmalı erkek hastalarda dört kat fazla bulunmuştur. Kadın hastalarda, simfizis diastazı bu tarz disfonksiyonlara yol açabilir. Bu hastalarda, deplase kırık parçasının vajina duvarını itmesi ile disparuni görülebilir. Lateral kompresyon kırıkları pelvik halka hacmini azaltarak normal fetüs geçişini zorlayabilir.

\section{Sinir Yaralanması}

Pelvik kırıklı hastalarda sinir yaralanma insidansı \%9-21 olarak rapor edilmiştir. ${ }^{[13,14]}$ Anterior pelvik halka yaralanmalarında pudendal sinir terminal dalları hasarı sonucunda impotans, inkontinans ve ağrı gelişebilir. ${ }^{[11]}$ Lindahl ve ark. ${ }^{[15]}$ Tile Tip C yaralanmalarda, 101 hastanın 40'ında lumbosakral pleksus hasarı rapor etmişlerdir. Stabil bir kaynama ve kabul edilebilir bir pozisyon elde edilemeyen kırıklarda, sinirin maruz kaldığı distraksiyon ve basıya bağlı olarak, sinir hasarı gelişme riski daha fazladır.

\section{RADYOLOJiK DEĞERLENDIRME}

Ağrı ve instabilitenin kaynaklandığı bölge, radyolojik olarak değerlendirilmelidir. Standart AP, inlet, outlet ve $45^{\circ}$ oblik düz grafiler çekilmelidir. İnstabilite, pelvik kompresyon ve distraksiyon testleri yapılarak klinik olarak test edilebilir. Asetabular bir kaynamama varsa, iliak ve obturator oblik görüntüler kolonların ve duvarların deplasmanı ile ilgili önemli bilgiler verir. Üç boyutlu bilgisayarlı tomografi kırık anatomisinin belirlenmesinde çok etkindir.

\section{TEDAVi}

Pelvis veya asetabulumda kaynamaması mevcut hastalarda tedavi planı, ağrının nedeni, eşlik eden başka pelvik deformite olup olmadığı ve hastanın beklentileri göz önüne alınarak yapılmalıdır.

Böyle olguların cerrahisinde karşımıza temel olarak üç farklı durum çıkabilir:

1) Temizlenebilir kallus.

2) Organize kaynamama.

3) Organize yanlış kaynama. ${ }^{[7]}$
Ameliyata alınma süreci ne kadar uzarsa cerrahın iyi bir redüksiyon elde etme şansı da o kadar azdır.[16]

Kırıkların ilk açık redüksiyon tedavisinden sonraki kaynamama oranı \%0-2 arasındadır. ${ }^{[17,18]}$ iliosakral çıkığın perkütan vida stabilizasyonunda kaynamama oranı \%7'ye kadar çıkmaktadır. ${ }^{19-22]}$ ìhmal edilmiş pelvik kırık olgularında uzun dönem sonuçları genellikle başarısızdır. Hastaların çoğunda tam iyileşme ve ağrısız ambulasyon sağlanamamaktadır. Bu hastalarda fonksiyonların restore edilmesi için, tam anatomik redüksiyon ve stabil internal tespit şarttır. Bu tür kaynamama olgularının tedavisi geç dönemde daha zordur ve komplikasyon gelişme ihtimali yüksektir. Fonksiyonel sonuçlar tam olarak öngörülemese de, fonksiyonları geri kazanmak için en iyi yöntem cerrahi tedavidir. Ameliyat öncesi planlamanın titizlikle yapılması şarttır. Tedavi seçenekleri, kırık konfigürasyonuna veolguya göre belirlenmeli, operasyonlar pelvik cerrahide deneyimli bir cerrah tarafindan yapılmalıdır. ${ }^{[3]}$

\section{Konservatif Tedavi}

Hafif deplase olan kırıklar ve stabil bir dizilim bozukluğuna yol açan kaynamamış kırıklar konservatif metodlarla takip edilebilir. Bacak uzunluk eşitsizliğinde, ayakkabı içi yükselticiler verilebilir. Kemik çıkıntıların oturma sırasında ağrı yapan hastalarda pelvik pedler verilebilir.

\section{Cerrahi Tedavi}

Semptomatik pelvik kırık kaynamama olgularında cerrahi korreksiyon tercih edilmelidir. ${ }^{[23]}$ Cerrahi tedavi prensipleri diğer kemik kaynamama olguları için olanlara benzerdir. Burada amaç; kaynamama bölgesinin debridmanı, kırık uçlarının yaklaştırılması, aradaki boşluğun kemik grefti ile doldurulması ve stabil internal tespittir. ${ }^{[3]}$

Pelvik kırık kaynamama ve yanlış kaynama olguların redüksiyonu zordur ve genişletilmiş yumuşak doku gevşetmeleri gerektirir. Bu ameliyatlar birkaç evrede yapılabilir. Ameliyat süresi uzundur ve ciddi miktarda kanamaya yol açabilir. ${ }^{[24]}$ Bunun bir nedeni de, bu hastalarda dizilim bozukluğu nedeniyle damar anatomisinin yer değiştirmesi ve normale göre varyasyon göstermesidir. ${ }^{[24]}$

İzole internal ve eksternal rotasyon, hemipelvisin izole posterior deplasmanı olan olgularda düzeltme nispeten daha kolaydır. ${ }^{25,26]}$ Sakroiliak eklemin posterior stabilizasyonu, perkütan SI vidalarla veya açık redüksiyon sonrası sakral iliak bar/rod veya plaklar ile sağlanabilir.

Literatürde en geniş cerrahi tedavi edilmiş ihmal edilmiş pelvik kırık olguları, Mears ve Velyvis ${ }^{[3]}$ tarafından yayımlanan 204 olgudur. Yazarlar, olgularının 

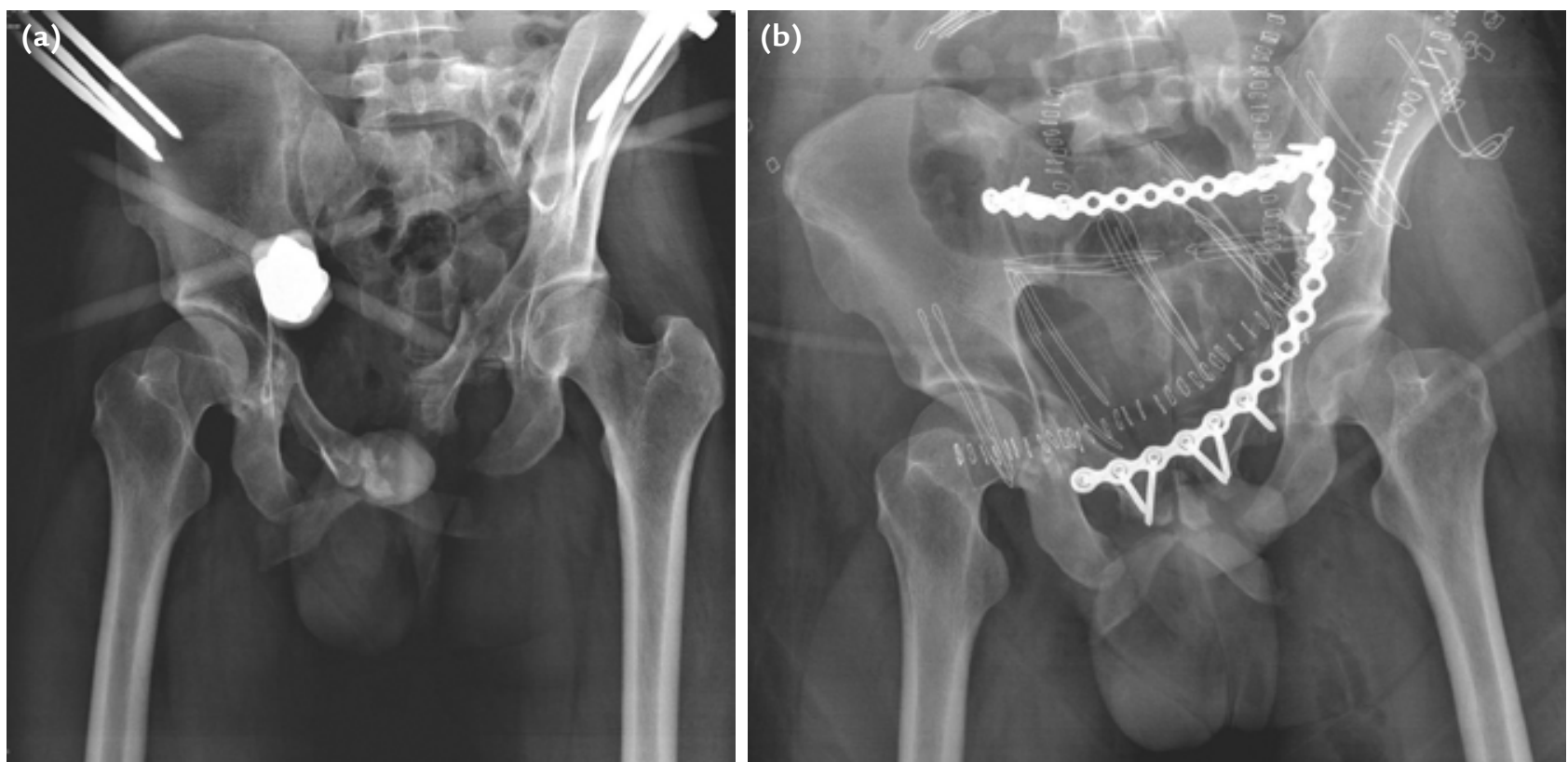

Şekil 1. a, b. Yirmi altı yaşında erkek hasta. Yurtdışında geçirdiği vertikal instabil Tile Tip C yara-lanma sadece eksternal fiksatör ile tedavi edilmeye çalışılmış. Ameliyattan iki ay sonra simfisis pubiste ve sol sakral kanatta kaynama yokluğu tespit edildi ve operasyon planlandı (a). Üç aşamalı olarak önce prone pozisyonda posterior sakro-iliak gevşetme uygulandı, fibröz skar dokuları ve posterior saroiliak ligamanlar temizlendi. Genişletilmiş ilioinguinal insizyon ile anteriordan 14 de-likli plak ile sol iliak kanattan sağ pubik kolu da içine alacak şekilde her iki hemi-pelvis önden bir-leştirildi. Üçüncü aşamada hasta tekrar prone pozisyona çevrilip posterior gergi bandı plağı ile tespit yapıldı (b).

\%96'sında kaynama elde ettiklerini bildirmişler, pelvik kırık kaynamama olgularında üç kolon teorisini ortaya koymuşlardır. Buna göre kolonlar:

1) Simfizis ve pubik kollar,

2) Sakral gövde ve SI eklemler,

3) Posterior sakral bağlardır.

íkinci kolonun iliosakral vidalar veya anterior sakroiliak plak ile, üçüncü kolonun posterior gergi bandı plağı ile tespitini savunmuşlardır. Bu prensibe göre düzeltme ve tespit uyguladıkları olgularda, ayakta durma dengesi, arka iliak çıkıntı ve üretra obstrüksiyonu konusunda başarılı sonuçlar bildirmişlerdir. Oturma dengesizliğinde ise \%64 ile daha az başarı bildirmişlerdir. Kompleks deformite düzeltmede başarısız olunan olguların bazılarında intakt hemipelvisten iskial tüberkül rezeksiyonu uygulamışlar ve başarılı sonuç etmişlerdir.

Kompleks vertikal instabil pelvik kaynamama ve yanlış kaynamalarda şu prosedürü izlemek gerekir: Önce prone pozisyonda iliak krestten inferiora, sakrum lateraline kadar vertikal bir insizyonla geniş bir posterior gevşetme uygulanır. Bu gevşetme sakro-iliak eklem, sakrum, posterior iliumu rahatlatmak; bunun yanı sıra skarlı sakro-iliak, sakro-tüberöz ve sakro spinöz bağları eksize etmek şeklindedir. Sonra supin pozisyonda, hem ön hem arka deformite ve kaynamama bölgeleri açılır, gevşetilir, düzeltilir, redükte ve fikse edilir. Ardından, hasta tekrar prone pozisyona getirilip posterior pelvik halka redükte ve stabilize edilir (Şekil 1). ${ }^{[3]}$

\section{KAYNAKLAR}

1. Dickson KF. Acetabular and Pelvic Nonunions. In: Agarwal A, editor. Nonunions. Diagnosis, Evaluation and Management. Boston: Springer; 2018. pp.183-205.

2. Pennal GF, Massiah KA. Nonunion and delayed union of fractures of pelvis. Clin Orthop Rel Res 1980;(151):124-9.

3. Mears DC, Velyvis J. Surgical reconstruction of late pelvic post-traumatic nonunion and malalignment. J Bone Joint Surg Br 2003;85(1):21-30.

4. Mears DC, Velyvis $\mathrm{JH}$. In situ fixation of pelvic nonunions following pathologic and insufficiency fractures. J Bone Joint Surg 2002;84-A(5):721-8.

5. Kanakaris NK, Angoules AG, Nikolaou VS, Kontakis G, Giannoudis PV. Treatment and outcomes of pelvic malunions and nonunions: a systematic review. Clin Orthop Relat Res 2009;467(8):2112-24. Crossref

6. Matta JM, Dickson KF, Markovich GD. Surgical treatment of pelvic nonunions and malunions. Clin Orthop Relat Res 1996;(329):199-206.

7. Letournel E. Diagnosis and treatment of nonunions and malunions of acetabular fractures. Orthop Clin North Am 1990;21(4):769-88. 
8. Mears DC, Rubash HE, Sawaguchi T. Fractures of the acetabulum. Hip 1985:95-113.

9. Helfet DL, Schmeling GJ. Management of complex acetabular fractures through single nonextensile exposures. Clin Orthop Relat Res 1994;(305):58-68.

10. Mohanty K, Taha W, Powell JN. Non-union of acetabular fractures. Injury 2004;35(8):787-90. Crossref

11. Wright JL, Nathens AB, Rivara FP, MacKenzie EJ, Wessells $H$. Specific fracture configurations predict sexual and excretory dysfunction in men and women 1 year after pelvic fracture. J Urol 2006;176(4 Pt 1):1540-5. Crossref

12. Oliver CW, Twaddle B, Agel J, Routt ML Jr. Outcome after pelvic ring fractures: evaluation using the medical outcomes short form SF-36. Injury 1996;27(9):635-41.

13. Schmal $H$, Markmiller $M$, Mehlhorn AT, Sudkamp NP. Epidemiology and outcome of complex pelvic injury. Acta Orthop Belg 2005;71(1):41-7.

14. Reilly MC, Zinar DM, Matta JM. Neurologic injuries in pelvic ring fractures. Clin Orthop Relat Res 1996;(329):28-36.

15. Lindahl J, Hirvensalo E. Outcome of operatively treated type-C injuries of the pelvic ring. Acta Orthop 2005;76(5):667-78. Crossref

16. Dilogo IH, Tobing JFL. Neglected acetabular fracture: Fix or replace? J Clin Orthop Trauma 2017;8(Suppl 1):S3-10. Crossref

17. Cole JD, Blum DA, Ansel LJ. Outcome after fixation of unstable posterior pelvic ring injuries. Clin Orthop Relat Res 1996;(329):160-79.

18. Templeman D, Goulet J, Duwelius PJ, Olson S, Davidson M. Internal fixation of displaced fractures of the sacrum. Clin Orthop Relat Res 1996;(329):180-5.
19. Jacob AL, Messmer P, Stock KW, Suhm N, Baumann B, Regazzoni $P$, Steinbrich W. Posterior pelvic ring fractures: closed reduction and percutaneous $C T$-guided sacroiliac screw fixation. Cardiovasc Intervent Radiol 1997;20(4):285-94.

20. Routt MLJr, Simonian PT, Mills WJ. Iliosacral screw fixation: early complications of the percutaneous technique. J Orthop Trauma 1997;11(8):584-9.

21. Starr AJ, Walter JC, Harris RW, Reinert CM, Jones AL. Percutaneous screw fixation of fractures of the iliac wing and fracture-dislocations of the sacro-iliac joint (OTA Types 61B2.2 and 61-B2.3, or Young-Burgess "lateral compression type II" pelvic fractures). J Orthop Trauma 2002;16(2):116-23.

22. Ebraheim NA, Savolaine ER, Skie MC, Baril J. Longitudinal fracture of the sacrum: case report. J Trauma 1994;36(3):447-50.

23. Sen RK, Goyal T, Tripathy SK. Neglected pelvic fractures: An overview of literature. J Orthop Traumatol Rehabil 2014;7(1):43-7. Crossref

24. Choi K-C, Ha J-Y, Kim W-Y. Surgical Correction and Osteosynthesis for Cranial Displaced Pelvic Nonunion: Technical Note and Two Cases Report Regarding Anterior Correction and Osteosynthesis Following Posterior Release. J Korean Fract Soci 2014;27(2):151-6. Crossref

25. Oransky M, Tortora M. Nonunions and malunions after pelvic fractures: why they occur and what can be done? Injury 2007;38(4):489-96. Crossref

26. Frigon VA, Dickson KF. Open reduction internal fixation of a pelvic malunion through an anterior approach. J Orthop Trauma 2001;15(7):519-24. 